\title{
Orthodontic occlusion and temporary removable retainers
}

\author{
I.Bonafe ${ }^{1}$, V. Lachiche ${ }^{3}$, J.-C. Egea ${ }^{1}$, D. Lhermet ${ }^{4}$, P. Canal ${ }^{2}$ \\ 1 Lecturer and hospital physician, Odontology Research and Teaching Unit, \\ University of Montpellier, France \\ 2 Professor, Odontology Research and Teaching Unit, University of Montpellier, France \\ ${ }^{3}$ Hospital physician, Odontology Research and Teaching Unit, University of Montpellier, France \\ ${ }^{4}$ Registrar, Odontology Research and Teaching Unit, University of Montpellier, France
}

\begin{abstract}
Implementing retention at end of orthodontic treatment is not straightforward: it may induce harmful side-effects on occlusion, muscles, joints and posture.

To foresee and prevent such risks, exhaustive clinical examination should be performed ahead of the retention phase: history taking, intra- and extra-oral examination, and static and dynamic analysis. The choice of type of retention appliance will result from this appraisal:

The practitioner should be rigorous in producing the device (form and choice of material), fitting it (fixity, stabilization), adjusting it (balance), and above all in follow-up.

Whatever the selected retention system, regular clinical follow-up is mandatory, to monitor ongoing adaptive balance: teeth, joints, muscles, etc.
\end{abstract}

\section{KEY WORDS}

Removable retention, occlusion, temporomandibular dysfunction, bruxism, posture

\section{INTRODUCTION}

Temporary removable retention is implemented at the end of orthodontic treatment, to fix, maintain and stabilize inter-dental relations so as to limit relapse and secondary migration?. We should, however, speak not so much of "retention" as of "retentions", so numerous are the potentially destabilizing pathophysiological mechanisms generated by treatment. The literature on periodontal ligament fiber reorganization is rich $^{14,30}$ and dental units certainly need to be blocked; but other factors also need to be taken into account, such as inter-dental relations in occlusion and during functional mandibular movement ${ }^{28}$, soft tissue pressure on the arcades and respiratory pressure on the nasal cavities. The choice of retention should thus be carefully made in the light of all of these criteria, specific to the individual patient.

\section{Address for correspondence:}

Isabelle Bonafe

545, Avenue du Pr Jean-Louis Viala

34193 Montpellier, France.

E-mail: dr.isabelle.bonafe@gmail.com

Article received: 03-07-2015. Accepted for publication: 29-07-2015.

This is an Open Access article distributed under the terms of the Creative Commons Attribution License (http://creativecommons.org/licenses/by/4.0), which permits unrestricted use, distribution, and reproduction in any medium, provided the original work is properly cited. 
Whatever the type of device, fitting needs to respect the various components of the masticatory (dental, osteoarticular and neuromuscular) system. If any of these fail, progressive imbalance ensues; this is known as dysfunction, and may lead to relapse and/or postural imbalance.

\section{CLINICAL EXAMINATION}

Clinical examination is specific, and should be detailed. It comprises extra- and intra-oral examination and static and dynamic analysis, to provide a global view of the masticatory system.

It allows screening for latent or manifest pathology, confirms the choice of retention, and also informs the patient on the need to adhere to the treatment program.

\section{Extra-oral examination}

\section{Muscle assessment}

Bimanual symmetric palpation, at rest then with the arcades closed, reveals muscle volume (hyper- or hypo-trophy), asymmetry and/or asynchrony, but also tension, sensitivity and myalgia, reflecting neuromuscular irritation (fig. 1).

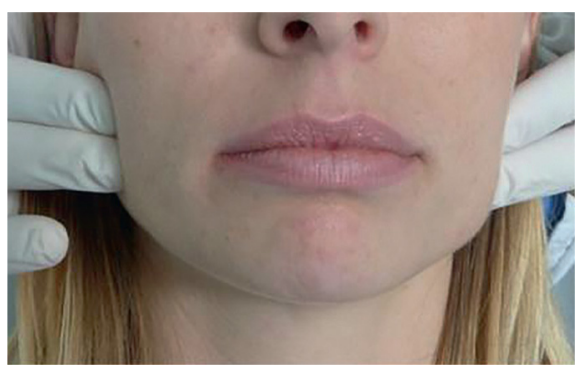

Figure 1

Masseter muscle palpation.
Implementing temporary retention is a phase of treatment in itself, determining overall success or failure ${ }^{3}$.

It is thus essential, before proceeding to retention, to perform thorough clinical examination, enabling global diagnosis that goes beyond the presenting dysmorphism.

Hypotrophy suggests occlusion disorder or hypofunction in some occlusal sectors. Hypertrophy is often associated with a parafunction, which needs to be detected. Muscles are liable to be strained by parafunctional activity such as bruxism, and the strain may be symmetrical or asymmetrical, inducing short- to longterm orodental and possibly postural forces and tension that may lead to severe imbalance ${ }^{4}$.

Any pain should be assessed in terms of intensity and also of loca-

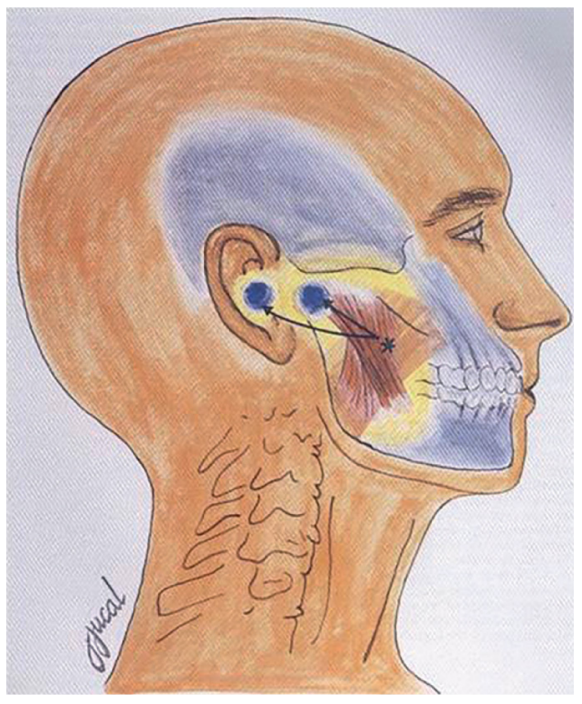

Figure 2

Masseter muscle (superficial and deep bundle) (Jankelson). 
tion, which varies according to the muscles involved ${ }^{11}$.

For example, masseter muscle spasm in the superficial or deep bundle induces:

- radiating (primary) pain nearby, in the cheek or gonial angle;

- projected (referred) pain, remote from the masseter, in the maxilla, mandible, temple, eyelid, temporomandibular joint (TMJ) or ear ${ }^{12}$. Starting from a trigger region, such pain spreads outward in remote areas having the same neurologic dermatome (fig. 2).

\section{Articular assessment}

\section{TMJ palpation}

TMJ palpation is bimanual, with comparison between left and right side, performed with the mouth closed and open, in the pre-auricular (external) and retro-auricular and intra-auricular regions. It assesses mandibular condyle morphology, with possible alteration of form or position.

Condyle displacement should be symmetrical and synchronous. Any snap, jerk or asymmetry is an alarm signal to be taken into account in screening for dysfunction.

Articular noise ${ }^{6}$ is explored; depending on its characteristics (snapping, cracking, reciprocity, etc.) and clinical signs (mandibular trajectory deviation), condylo-discal system pathology may be diagnosed.

\section{Intra-oral examination}

\section{Dental assessment}

On removing orthodontic casing, decay, tooth fracture, requirements for dental treatment or prostheses to be replaced may contraindicate immediate retention, and should be dealt with as quickly as possible so as to be able to work on a favorable diathesis.

Dental abrasion, mylolysis, cracks, gum recession, alveolysis and hypercementosis are alarm signs for parafunction (fig. 3).

\section{Occlusion assessment}

Occlusal relations are assessed statically and dynamically (fig. 4).

Quality and quantity of dental contact symmetry, occlusion plane, Spee and Wilson bends, and molar occlusal side orientation are important factors for stability when optimal.

Slight rotation due to incomplete correction should be screened for, as it may represent incipient relapse and induce interference or prematurity, preventing normal occlusion.

Molar chocking should be checked, and cusp-fossa relations, if not optimal, should be corrected by addition of substance.

Oral opening, with a height of around $50.7 \pm 7 \mathrm{~mm}^{24}$, should be vertical and straight. Limitation or disorders such as deviation or deflection are alarm signals for joint or muscle pathology.

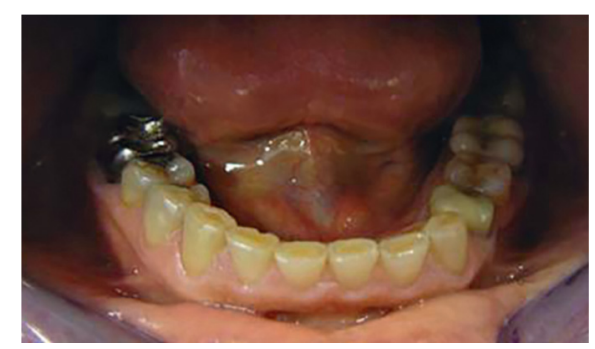

Figure 3

Dental abrasion. 


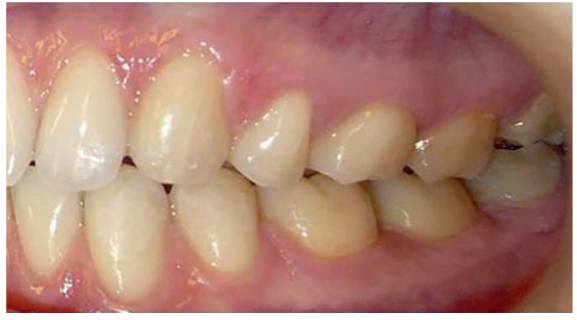

Figure 4

Static occlusal relations (maximum intercuspation).

Propulsion and lateral movement should be harmonious, balanced and integrated in ideal mandibular kinematics ${ }^{20}$. Any abnormality disturbs the masticatory cycle, with severe long-term consequences ${ }^{16}$.

Occlusion pattern analysis is primordial, confirming the chocking, centering and guidance functions that guarantee functional balance and long-term stability ${ }^{21}$.

\section{Periodontal assessment}

It is essential to assess the state of dental support, rendered sensitive by the phenomena of apposition and resorption inevitably induced by displacing teeth ${ }^{32}$, and to ensure absence of mobility.

According to Paulson ${ }^{23}, 4$ years are needed for desmodontal fibers to reorganize; the patient needs to be aware of this.

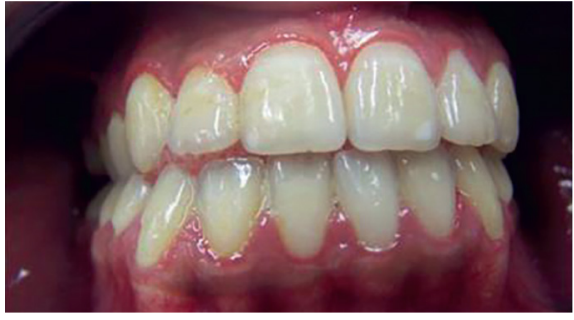

Figure 5

Lingual dyspraxia.

\section{Oral function assessment: swallowing, phonation and respiration (fig. 5)}

Tongue dysfunction (interposition, abnormal swallowing, low tongue, etc.) and bad habits such as nail-biting can affect mandibular positioning and thus occlusal relations ${ }^{13}$.

Strong muscle and soft-tissue pressure on the arcades (hypertonus) or oral breathing frequently cause relapse and should be screened for systematically ${ }^{8}$.

Following this clinical examination, dysfunction may or may not be diagnosed.

Any pathology must either be managed before fitting removable retainers or taken account of in choosing and balancing the retention system.

Even if there is no dysfunction, it seems to us to be important to be aware of the factors liable to lead to or trigger onset.

\section{TEMPOROMANDIBULAR JOINT (TMJ) DYSFUNCTION}

TMJ dysfunction is defined as symptomatic expression of temporomandibular myoarthropathy, and usually displays impaired mandibular kinematics with or without associated pain or joint noise. It is well classified, as muscular, articular or musculo-articular TMJ dysfunction.

Etiology is multifactorial (occlusal factors, parafunctions, trauma, 
hypermobility, stress, personality, etc.) and onset basically depends on the capacity for adaptation, which varies from individual to individual and over time for a given individual.

Occlusal factors and their implication in TMJ dysfunction were controversial for many years, but are now subsumed under a global etiology, as predisposing or trigger factors.

Imbalanced occlusal contacts (hooks or resin) cause interference and prematurity, regularly deviating the mandible during closure. Occasional closed bite in a non-stabilized (recent retention) or pathological periodontal context develops toward occlusal trauma, causing version or ingression of the antagonist teeth.

Such occlusion, when it becomes pathological and pathogenic, positions the mandible non-physiologically, inducing periodic mechanical overload between the various joint components ${ }^{11}$. Onset of structural or behavioral stress may aggravate occlusal imbalance, leading to TMJ dysfunction.

So long as adaptation-reduction, adaptation-transformation balance is maintained, the subject will be asymptomatic, but any loss of ho- meostatic balance leads to structural, impairment ${ }^{22}$.

That parafunctions such as bruxism, possibly aggravated by psychological or general disorder, are implicated is no longer disputed.

Parafunction is defined as involuntary, non-functional, rhythmic or spasmodic masticator muscle activity, and may take 2 well-defined forms: centered and excentric bruxism ${ }^{15}$.

Centered bruxism (clenching) involves isometric contraction without displacement of bone elements, and usually occurs when the subject is awake; it generally leads to muscular hypertrophy.

Excentric bruxism (grinding) involves isotonic contraction, with displacement of bone elements, and usually occurs when the subject is asleep; it leads to usually asymmetric changes in masticator muscle tonus.

Commisso $^{5}$, in a 2014 study, showed that shear stress in bruxism, especially when centered, could damage the joint disc, ending in TMJ dysfunction.

The chosen retention device must therefore not be iatrogenic, and even be possible to use in managing certain dysfunctions.

\section{TEMPORARY REMOVABLE RETAINERS AND POSSIBLE SIDE-EFFECTS}

Harmonizing anterior and posterior sector functional relations is a mandatory first step in retention.

To avoid breaking the balance, certain criteria should be respected, in producing (shape, choice of material), fitting (fixing, stability) and balancing temporary removable retention.

We shall deal here only with monomaxillary devices: Hawley plate, and thermoformed splint. 


\section{Removable Hawley plate (fig. 6)}

\section{Description and advantages}

Hard resin Hawley palatal plates are stabilized by 2 Adams hooks $(1$ mesial in the first premolar and 1 distal in the first molar) or prosthetic hooks, with a stainless steel wire from canine to canine, ensuring fixity.

The rigidity of the material prevents relapse of arcade width after expansion, while maintaining rotational correction related to tooth morphology; the main purpose of a retention device is to counteract gum fiber tension, which tends to pull the teeth back to their original position.

The plate allows vertical adaptation of the teeth to the new setting, with good transverse control ${ }^{10}$; it thus enables the oro-dental system to adapt progressively to the new neuromuscular-articular balance. According to Littlewood18, the teeth end up by positioning themselves, with better distribution of occlusal contact.
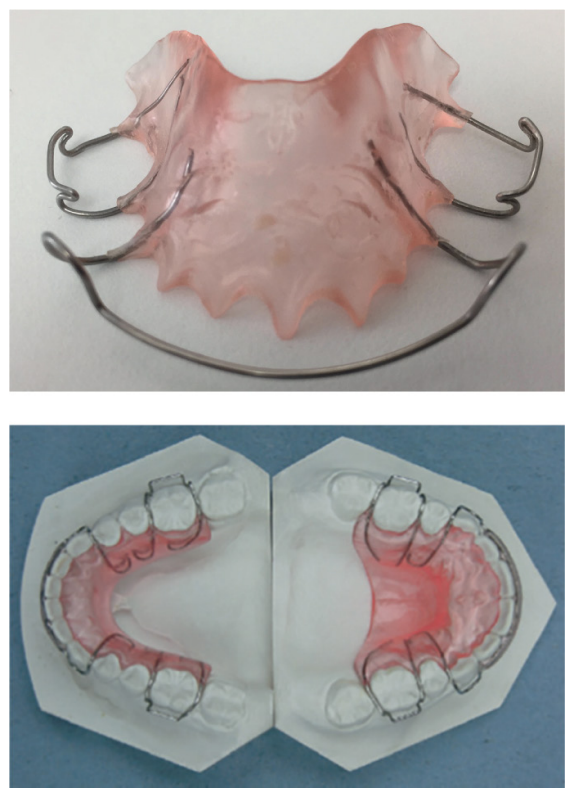

Figure 6

Removable Hawley plates.
Occlusion in precise, balanced maximum intercuspation, respecting the tripod principle and cusp/fossa relations, is important for the stability of tooth positioning.

\section{Essential criteria}

To optimize efficacy, the plate should be carefully positioned, taking account of the risk of occlusal or articular imbalance that it may incur.

\section{Occlusion}

On the day of fitting, occlusion should be checked without the plate and balanced if necessary so that retention is integrated in a theoretically "ideal" occlusion pattern. As it takes time to produce the device, changes may occur in the teeth between molding and fitting. According to Reitan ${ }^{26}$, the first movements toward relapse occur as soon as active treatment is terminated.

Relations between the tooth and the antagonist wire are controlled, and any interference or closed bite should be eliminated, to avoid occlusal trauma in the tooth in question.

Another major drawback of the Hawley plate is the lack of control of anterior teeth, with risk of incisor guide egression.

Removing the plate reveals lack of posterior contact, which has incontestably harmful effects on the temporomandibular joint.

This type of retention is obviously contraindicated if joint pathology has been diagnosed and not treated.

\section{Wearing the Hawley plate}

"Part-time" use, often due to the discomfort of a rather bulky device, leads to occlusal imbalance, inducing 
interference and prematurity.

Occasional closed bite (occlusal trauma) leads to repeated sliding movements that are very harmful for the periodontium, inducing mobility and version in the teeth in question, progressively altering the initial occlusion and deviating the mandible during closure.

"Full-time" use can also have occlusal side-effects, often inducing slight maxillary arcade expansion; if this is not mirrored in the mandibular arcade, which remains narrow, occlusion is destabilized. The maxillary expansion may resolve once the plate is removed, but in the worst case scenario lateral mandibular displacement becomes chronic, impacting the TMJ.

Whether full- or part-time use is prescribed, adherence is patientdependent and regular monitoring of occlusal balance should be scheduled.

\section{Thermoformed splint (fig. 7)}

\section{Description and advantages}

Thermoformed splints can be maxillary as well as mandibular; they are usually transparent, and much less bulky than Hawley plates ${ }^{1,9}$.

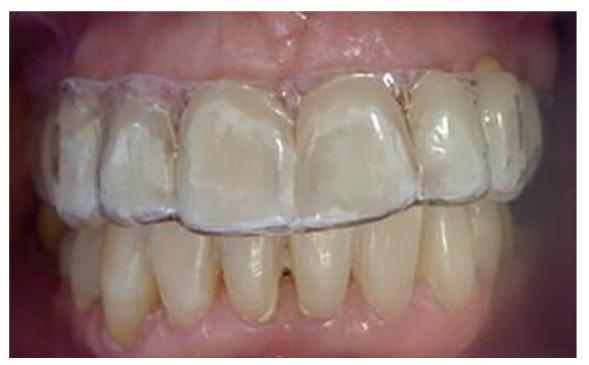

Figure 7

Thermoformed splint.
The splint covers all of the crowns of the arcade, "theoretically" ensuring 3-dimensional retention.

Fixity is provided by the elasticity of the material.

Not being very bulky, it is wellaccepted and worn between 8 and 22 hours a day. In the USA, it is used for $36 \%$ of retentions ${ }^{29}$.

\section{Essential criteria for the thermofor- med splint to remain "neutral" for teeth, muscles and joints}

\section{Choice of material}

The splint is in resin, but the choice of material (flexible or rigid) is important, as it impacts certain biological parameters $^{25}$.

Some authors argue that soft resin leads to tension and gritting the teeth: Rozencweig ${ }^{27}$ even reported biting and chewing reflexes with this type of device. In a 1998 study, Okeson ${ }^{19}$ reported increased electromyographic activity in $50 \%$ of soft-splint wearers. Lindfors ${ }^{17}$, on the other hand, disagreed and claimed that nothing goes to show that the choice of material affects control of nocturnal bruxism. However, in 2012 Arima compared results with soft versus hard splints in severe bruxism²: electromyography showed $80 \%$ less nocturnal muscle activity with hard splints; he explained this by the fact that flexible material does not greatly inhibit muscle activity during sleep, unlike a rigid splint.

Choice of material thus seems to be an important step, due to its neurobiological impact on masticator muscle regulation. Rigid orthoses are well-known to temporarily inhibit masticator muscle activity, acting directly on the tendency to grit the teeth. 


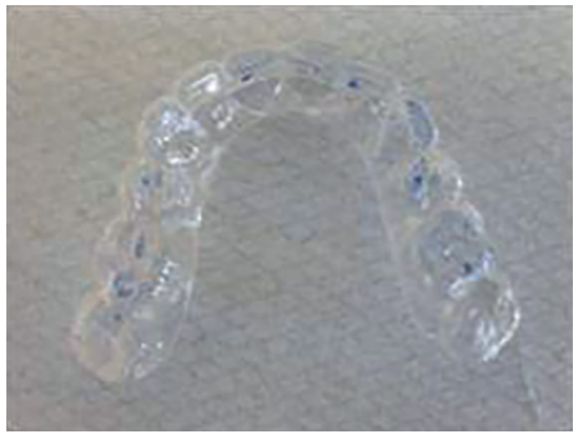

Figure 8

Splint balance.

Rigid resin retention is also indisputably easier to balance, providing stability for the intermaxillary relation concerned $^{31}$ (fig. 8).

Moreover, soft-resin occlusal splints are too flexible to maintain the arcade transversally, especially in case of maxillary expansion; they deteriorate faster and are almost impossible to

\section{CONCLUSION}

Retention after active treatment is indispensable and should not be neglected, as it stabilizes treatment results.

It reduces, without eliminating, the risk of immediate or progressive relapse that may follow orthodontic treatment.

It combats ligament elasticity and should also protect the whole mastication system. Only global post-orthodontic management can guarantee treatment stability.

This is why the retention should not hamper the "occlusal machinery", but should be as passive as possible. However, in some cases of joint pathology, it may not be simply neutral balance, leaving intermaxillary relations non-controlled.

Wearing the splint

Just like Hawley plates, splints should be worn continuously to avoid "jiggling", which harms the periodontium.

But this means that no process of occlusal adaptation is possible, due to lack of direct intercuspation between the arcades.

Whatever the type of retention, occlusion adjustment is an essential step: checking the new occlusal pattern induced by the temporary removable appliance is mandatory.

The new intercuspation occlusion should be well-balanced, both statically and dynamically, so as not to imbalance the masticator system as a whole.

but also contribute to treatment. We therefore opt mainly for rigid thermoformed splints, which seem easier to integrate into the mastication system.

Retention should be well-considered, well-performed, and wellbalanced. Whatever type is used, regular clinical check-ups are essential to monitor adaptive balance of the system as a whole: teeth, joints and muscles.

No temporary retention system is perfect: they are temporary, helping limit one of the most difficult problems in orthodontics: relapse.

Conflict of interest: The authors declare no conflicts of interest. 


\section{REFERENCES}

1. Amoric M. [Thermoformed orthopedic splints]. Actual Odontostomatol (Paris) 1990;(172):675-695.

2. Arima T, Takeuchi T, Tomonaga A, Yachida W, Ohata N, Svensson P. Choice of biomaterials: Do soft occlusal splints influence jaw-muscle activity during sleep? A preliminary report. Applied Surface Science 2012;262:159-162.

3. Canal P, Salvadori A (2008). Orthodontie de l'adulte : rôle de l'orthodontie dans la réhabilitation générale de l'adulte. Elsevier Masson.

4. Carra MC, Huynh NT, et al. Sleep bruxism, snoring, and headaches in adolescents: short-term effects of a mandibular advancement appliance. Sleep Med 2013;14: 656661.

5. Commisso MS, Martinez-Reina J, Mayo J. A study of the temporomandibular joint during bruxism. Int J Oral Sci 2014;6(2):116-123.

6. Corroy AS, Helfer M. La palpation musculaire: un acte clinique essentiel pour le diagnostic des dysfonctions de l'appareil manducateur. Cah Prothèse 2010;151:15-23.

7. Danan M, Fontanel F, Brion M. Parodontites sévères et orthodontie. Éditions CdP, 2004.

8. Delhaye-Thépaut G, Fournier M., et al. Savoir regarder pour éviter les récidives. Rev Orthop Dento Faciale 2003;37:429-441.

9. Gardner GD, Dunn WJ, Taloumis L. Wear comparison of thermoplastic materials used for orthodontic retainers. Am J Orthod Dentofacial Orthop 2003;124:294- 297.

10. Guez C, Philip-Alliez C. Contentions orthodontiques : revue de synthèse et protocoles cliniques. Revue d'Odonto Stomatologie 2011;40:261-279.

11. Jankelson B. Neuromuscular aspects of occlusion. Effects of occlusal position on the physiology and dysfunction of the mandibular musculature. Dent Clin North Am 1979;23:157-168.

12. Jankelson RR. Neuromuscular dental diagnosis and treatment. St. Louis. Ishiyaku EuroAmerica, 1990.

13. Julien P. Les multiples causes de la récidive. Orthod Fr 2005;76(3).

14. Julien P. De la contention. Orthod Fr 2010;81(3):221-226.

15. Lavigne GJ, Khoury S, Abe S, Yamaguchi T, Raphael K. Bruxism physiology and pathology: an overview for clinicians. J Oral Rehabil 2008;35(7):476-494.

16. Le Gall M, Lauret J, Eds. (2002). Occlusion et fonction: une approche clinique rationnelle. Éditions CdP.

17. Lindfors $E$, Magnusson T, Tegelberg A. Interocclusal appliances--indications and clinical routines in general dental practice in Sweden. Swed Dent J 2006;30:123- 134.

18. Littlewood SJ, Millett DT, Doubleday B, Bearn DR, Worthington HV (2006). Orthodontic retention: a systematic review. J Orthod 33: 205-212.

19. Okeson JP. Management of temporomandibular disorders and occlusion. Elsevier Health Sciences, 2014.

20. Orthlieb JD. La fonction de guidage. Un modèle biomécanique pour un concept thérapeutique. Cah Proth 2004;128:55-64.

21. Orthlieb JD, Darmouni L, Pedinielli A, Jouvin Darmouni J. Fonctions occlusales: aspects physiologiques de l'occlusion dentaire humaine. EMC-Médecine Bbuccale 2013;8(1):1-11.

22. Orthlieb JD, Deroze D, Lacout J, Maniere Ezvan A. Occlusion pathogène et occlusion fonctionnelle : définitions des finitions. Orthod Fr 2006;77:451-459. 
23. Paulson RC. A functional rationale for routine maxillary bonded retention. Angle Orthod 1992;62:223-226.

24. Placko G, et al. Normal mouth opening in the adult French population. Rev Stomatol Chir Maxillofac 2005;106:267-271.

25. Re JP, Chossegros C, El Zoghby A, Carlier JF, Orthlieb JD. Occlusal splint: state of the art. Rev Stomatol Chir Maxillofac 2009;110:145-149.

26. Reitan K. Principles of retention and avoidance of post-treatment relapse. Am J Orthod 1969;55:776-790.

27. Rozencweig D, Ed. Algies et dysfonctionnements de l'appareil manducateur. Éditions CdP, 1994.

28. Sauget E, Covell DA Jr, Boero RP, Lieber WS. Comparison of occlusal contacts with use of Hawley and clear overlay retainers. Angle Orthod 1997;67:223-230.

29. Singh P, Grammati S, Kirschen R. Orthodontic retention patterns in the United Kingdom. J Orthod 2009;36(2):115-121.

30. Tenshin S, et al. Remodeling mechanisms of transseptal fibers during and after tooth movement. Angle Orthod 1995;65:141-150.

31. Turk DC. Psychosocial and behavioral assessment of patients with temporomandibular disorders: diagnostic and treatment implications. Oral Surg Oral Med Oral Pathol Oral Radiol Endod 1997;83:65-71.

32. Vanderveken OM, Van de Heyning P, Braem MJ. Retention of mandibular advancement devices in the treatment of obstructive sleep apnea: an in vitro pilot study. Sleep Breath 2014;18:313-318. 